\title{
Amino acid imbalance in cystinuria
}

\author{
A. M. ASATOOR, P. S. FREEDMAN, J. R. T. GABRIEL, M. D. MILNE, \\ D. I. PROSSER, J. T. ROBERTS, AND C. P. WILLOUGHBY
}

From the Medical Unit, Westminster Medical School, London

SYNOPSIS After oral ingestion of a free amino acid mixture by three cystinuric patients, plasma? increments of lysine and arginine were lower and those of many other amino acids were significantlyo higher than those found in control subjects.

Similar results were obtained in control subjects after amino acid imbalance had been artificially induced by the omission of cystine, lysine, and arginine from the amino acid mixture. Especially응 high increments of alanine and proline provided the best evidence of amino acid imbalance causedo by a temporary lysine and, to a lesser extent, arginine and cystine deficit.

No such amino acid imbalance was found to occur in the cystinuric patients after ingestion of whole protein, indicating that absorption of oligopeptides produced by protein digestion provided $\bar{\Phi}$ a balanced physiological serum amino acid increment. This is considered to explain the lack of $\overrightarrow{0}$ any unequivocal nutritional deficit in cystinuric patients despite poor absorption of the essential $\stackrel{\perp}{\perp}$ free amino acid, lysine.

Impaired intestinal absorption of four free amino acids-cystine, lysine, arginine, and ornithine-has been proved to occur in cases of cystinuria by several independent methods (Milne, Asatoor, Edwards, and Loughridge, 1961; McCarthy, Borland, Lynch, Owen, and Tyor, 1964). Despite poor absorption of the essential amino acid lysine, cystinuric patients do not suffer from any detectable nutritional defect except for a slight reduction in average stature (Colliss, Levi, and Milne, 1963). This apparent anomaly has more recently been explained by the demonstration of a normal rate of intestinal absorption of oligopeptides containing lysine (Asatoor, Crouchman, Harrison, Light, Loughridge, Milne, and Richards, 1971; Hellier, Holdsworth, Perrett, and Thirumalai, 1972). Theoretically, therefore, cystinuric patients would be expected to show evidence of amino acid imbalance after ingestion of free amino acid mixtures but little of any such imbalance after protein meals. This paper reports the results of oral amino acid and protein tolerance tests, showing that such imbalance does, in fact, occur after amino acid intake but not after ingestion of whole protein.

\section{Methods}

Oral tolerance tests were carried out in three adult Received for publication 3 April 1974. homozygous cystinuric patients who were admitted $\stackrel{๊}{\varnothing}$ to hospital either for surgical removal of cystine $\stackrel{\varrho}{\circ}$ calculi or assessment of their suitability for future $\overrightarrow{\overrightarrow{0}}$ penicillamine therapy. They all gave their informed 3 consent to the investigation. The three patients were either type I or type II cystinurics (Rosenberg, 1966), and were all known to have severely impaired intestinal absorption of dibasic amino acids. Similar control tests were performed in eight normal adults, including 3 . all the authors of this paper. The tests were carried out in the early morning after an overnight fast. Each patient had two tests, separated by an interval 0 of more than three days. The protein absorption test consisted of ingestion of oral Casilan as a palat- $\frac{D}{0}$ able source of casein at a dosage of $385 \mathrm{mg} / \mathrm{kg}$ body weight suspended in $500 \mathrm{ml}$ water. Amino acids $\sigma$ were given as a mixture (see table), the amounts $N$ being designed to be equivalent to those in the N protein combination in the Casilan. The composi- $\frac{\omega}{\sigma}$ tion of the mixture was based on the results of analysis of the released amino acids after hydrolysis of a sample of Casilan for $24 \mathrm{hr}$ by $6 \mathrm{M} \mathrm{HCl}$ in a sealed evacuated tube at $100^{\circ} \mathrm{C}$. Glutamine and asparagine are hydrolysed by this procedure and in 0 the mixture were replaced by an equivalent amount $\mathbb{D}$ of glutamic and aspartic acids respectively. Tryptophan is completely destroyed by acid hydrolysis, and some serine and threonine are also degraded. These three amino acids (which are not involved in the 8 


\begin{tabular}{|c|c|c|}
\hline Amino Acid & $\mathrm{mmol} / 100 \mathrm{~g}$ & $\begin{array}{l}\text { Dose in Patients and } \\
\text { Controls ( } \mu \mathrm{mol} / \mathrm{kg} \\
\text { body weight) }\end{array}$ \\
\hline $\begin{array}{l}\text { L-glutamic acid } \\
\text { L-proline } \\
\text { L-leucine } \\
\text { L-serine } \\
\text { L-lysine } \\
\text { L-valine } \\
\text { L-aspartic acid } \\
\text { L-threonine } \\
\text { L-isoleucine } \\
\text { L-alanine } \\
\text { L-phenylalanine } \\
\text { L-tyrosine } \\
\text { Glycine } \\
\text { L-arginine } \\
\text { L-methionine } \\
\text { L-histidine } \\
\text { L-tryptophan } \\
\text { L-cystine }\end{array}$ & \begin{tabular}{r|}
$118 \cdot 0$ \\
$72 \cdot 0$ \\
$58 \cdot 5$ \\
$52 \cdot 3$ \\
$47 \cdot 1$ \\
$47 \cdot 0$ \\
$42 \cdot 2$ \\
$33 \cdot 4$ \\
$33 \cdot 0$ \\
$27 \cdot 6$ \\
$26 \cdot 6$ \\
$25 \cdot 4$ \\
$20 \cdot 1$ \\
$17 \cdot 8$ \\
$17 \cdot 1$ \\
$16 \cdot 0$ \\
$5 \cdot 4$ \\
$1 \cdot 1$
\end{tabular} & $\begin{array}{r}454 \\
277 \\
225 \\
201 \\
181 \\
181 \\
162 \\
129 \\
127 \\
106 \\
102 \\
98 \\
77 \\
69 \\
66 \\
62 \\
21 \\
4\end{array}$ \\
\hline
\end{tabular}

Table Composition of amino acid mixture equivalent to Casilan

experimental results of this paper) were added in the amounts stated to be contained in Casilan by the manufacturers. The results of our analyses of other constituent amino acids agreed closely with those reported by the makers. Venous blood samples were obtained immediately before the test and at 30,60 , and $90 \mathrm{~min}$ after ingestion of the protein or of the mixed amino acids.

Identical tests were carried out in the normal controls, but in addition a third free amino acid tolerance test designed to produce amino acid imbalance similar to that found in the cystinuric patients was also performed. This consisted of the intake of the free amino acid mixture (see table) without, however, inclusion of cystine, arginine, and lysine. Both in the patients and in the controls, evidence of amino acid imbalance was found in most cases to be maximal $60 \mathrm{~min}$ after ingestion of the free amino acid mixture. As this investigation was designed to determine the degree of the expected imbalance, only the increments of serum amino acid content between the 60 -min and the basal blood specimens are reported.

Amino acids in blood serum were determined with the Technicon amino acid analyser (Technicon Handbook, 1966). The method used does not adequately separate serine, threonine, glutamine, and asparagine and, therefore, no analyses of the concentrations of these amino acids are reported. In addition, changes in serum content of cystine and tryptophan were too small for accurate results to be obtained. The evidence for amino acid imbalance after free amino acid ingestion depends on analyses of the 14 remaining amino acids of the protein chain.

\section{Results}

COMPARISON OF INCREMENTS OF SERUM

AMINO ACIDS AFTER FREE AMINO ACID

INTAKE IN THE CYSTINURIC PATIENTS

AND THE CONTROLS

The increments of serum amino acids in the 60 min after amino acid ingestion are given in figure 1. Increments of serum lysine and arginine are lower in the patients than in the controls, increments of aspartic and glutamic acids are similar, whereas those of the remaining 10 amino acids are higher in

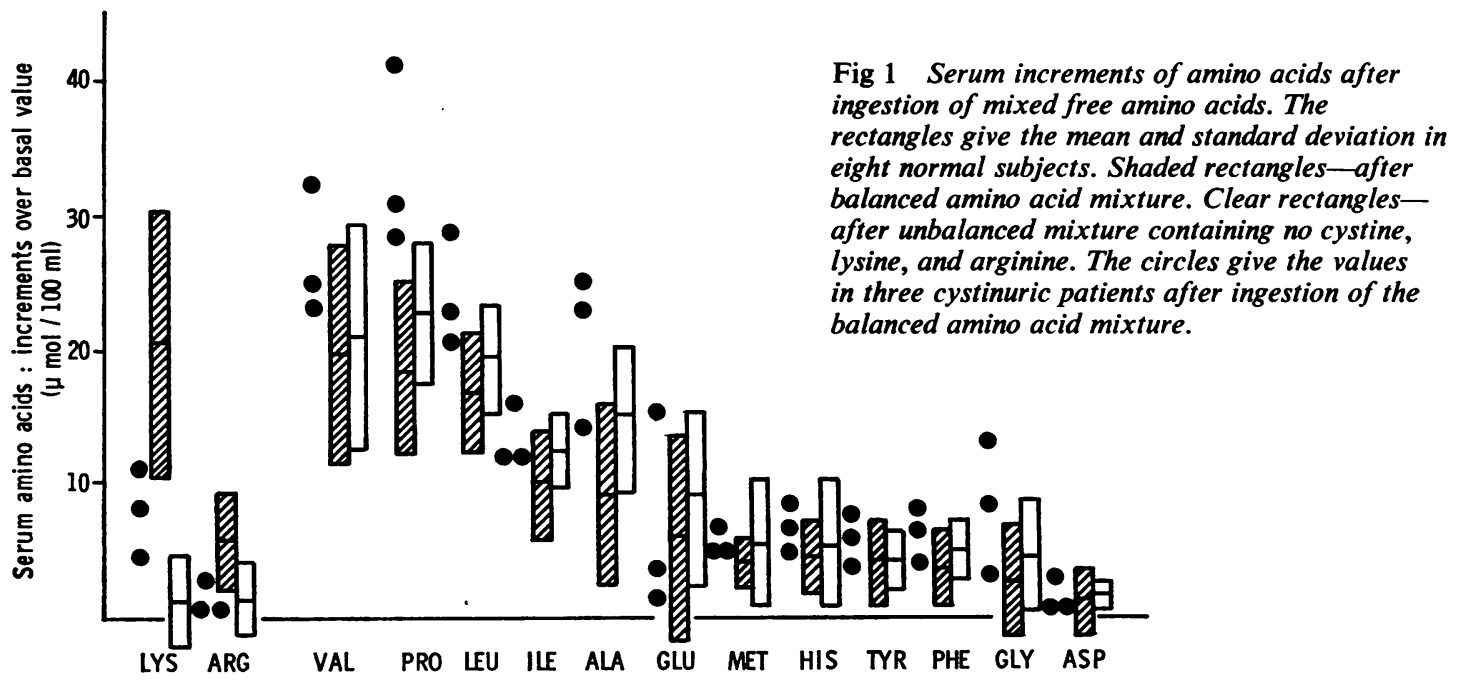

Fig 1 Serum increments of amino acids after ingestion of mixed free amino acids. The rectangles give the mean and standard deviation in eight normal subjects. Shaded rectangles-after in three cystinuric patients after ingestion of the balanced amino acid mixture. 
the patients than in the controls. Arguments are advanced later that this is due to amino acid imbalance induced by impaired absorption of lysine, arginine, and cystine by the patients. The number of observations in the patients are too few to allow statistical analysis of the results of each individual amino acid, but those showing especially high relative values in the patients are alanine, proline, valine, and leucine. Excluding the results of increments of serum lysine and arginine, where the low figures are a primary effect of reduced intestinal absorption, the serum increments of the other 12 amino acids studied collectively show a highly significant increase over normal control values $(\mathrm{t}=$ 4.76; $\mathrm{P}<0.001$ ).

The statistical technique used was conversion of each incremental value in the patients to units equal to the variance of the normal subjects. These values were then added together and the collective statistical deviations from the normal means analysed by the standard $t$ test.

\section{COMPARISON OF INCREMENTS OF SERUM AMINO ACIDS AFTER THE BALANCED AND THE DEFICIENT AMINO ACID MIXTURES IN THE NORMAL CONTROLS}

As expected, increments of serum lysine and arginine (fig 1) are significantly higher after the balanced than after the deficient amino acid mixture $(t=16 \cdot 1$; $P<0.001, t=5.32 ; P<0.01$ respectively), By contrast, increments of the other 12 amino acids are in general higher after the deficient than after the balanced amino acid mixture, the difference being statistically significant in the cases of alanine $(t=$ 5.65 ; $P<0.01)$, leucine $(t=3.06 ; P<0.05)$, phenylalanine $(\mathrm{t}=2 \cdot 88 ; \mathrm{P}<0.05)$, and proline $(\mathrm{t}=2.65$; $P<0.05)$. Taking the results collectively, but excluding those for arginine and lysine as primary inducers of the amino acid imbalance, the amino acid increments after the deficient mixture are significantly higher than those after the balanced mixture $(\mathrm{t}=2.41 ; \mathrm{P}<0.02)$.

\section{COMPARISON OF INCREMENTS OF SERUM} AMINO ACIDS AFTER INGESTION OF CASILAN IN THE PATIENTS AND IN THE CONTROLS Figure 2 shows that there is no obvious difference $\vec{\circ}$ in serum amino acid increments after Casilan $\overrightarrow{\vec{\omega}}$ ingestion in the patients and in the controls. Cor- $\stackrel{\omega}{\sigma}$ responding results were obtained at 30,60 , and 90 용 min after Casilan ingestion, but, as in the case of the free amino acids, only amino acid increments at $60 . \mathrm{V}$ min are reported. Statistical analysis of the collective results of the increments of the 12 amino acids 8 excluding lysine and arginine confirms that the two 은 series are numerically equivalent $(t=0.11 ; \mathrm{P}>⿻$ 0.90). In the controls, amino acid increments in the $c$ first $60 \mathrm{~min}$ were higher after the balanced amino acid mixture than after Casilan. The differences were statistically significant in the cases of leucine $(\mathrm{t}=5.57 ; \mathrm{P}<0.001)$, lysine $(\mathrm{t}=5.08 ; \mathrm{P}<0.01)$, valine $(\mathrm{t}=3.89 ; \mathrm{P}<0.01)$, methionine $(\mathrm{t}=3.89$; $P<0.01)$, and isoleucine $(t=2.36 ; P<0.05)$.

\section{Discussion}

Previous reports (Asatoor et al, 1972; Hellier et al, $\stackrel{\overrightarrow{0}}{\overrightarrow{0}}$ 1972) have shown that free lysine and arginine are $\frac{3}{3}$ poorly absorbed by cystinuric patients, but are more satisfactorily absorbed either from whole protein or as constituents of olipopeptides. The present results suggest that malabsorption of the affected amino acids-lysine, arginine, and cystine-in $\frac{5}{3}$ cystinuric patients caused considerable amino acid

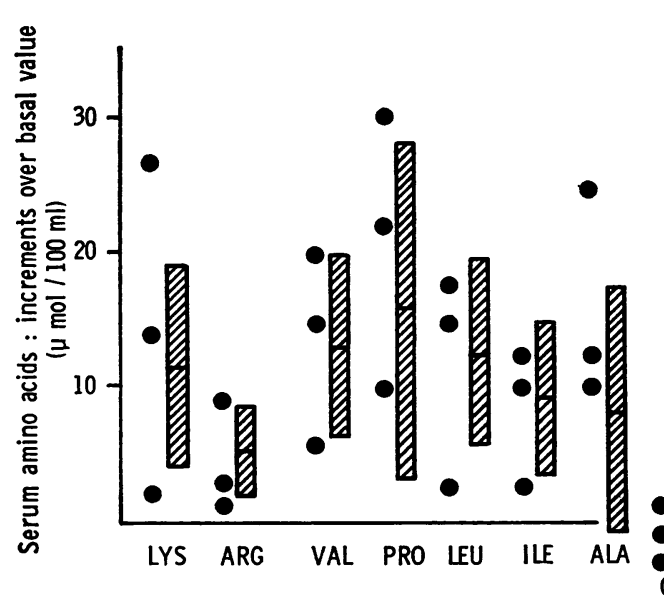

Fig 2 Serum increments of amino acids after ingestion of a standard amount of Casilan. The shaded rectangles give the mean and standard deviation in eight normal subjects, and the circles the values in three cystinuric patients.

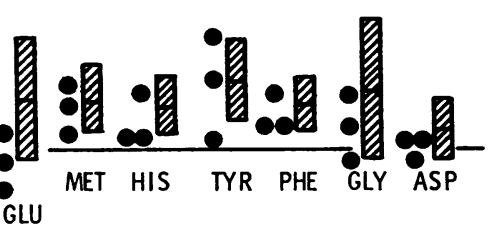


imbalance when amino acid mixtures are given by mouth, but that no such imbalance occurs when whole protein is fed. This explains why cystinurics show little if any evidence of nutritional impairment (Colliss et al, 1963) despite severe reduction in the rate of intestinal absorption of the free essential amino acid, lysine. Severe nutritional impairment and amino acid imbalance would almost certainly occur if a cystinuric patient were maintained on oral amino acid mixtures rather than on whole protein.

Increments of serum amino acids after the oral intake of proteins or of free amino acid mixtures are obviously related to the speed of protein digestion, to the rapidity of absorption of free amino acids or of oligopeptides from the gut lumen, and to the rate of removal of amino acids from the blood. Abnormally low increments of arginine and lysine in cystinurics after the intake of a free amino acid mixture are probably due to reduced intestinal absorption rates of the two compounds. Changes in urinary output of lysine and arginine during the first hour after ingestion of the free amino acid mixture were negligible and could not have explained the abnormally low plasma increments of the two amino acids. There is no evidence of increased absorption rates to account for the abnormally high increments of other amino acids, and therefore these must be due to reduced rates of their elimination from the blood. Amino acids are removed from the blood by equilibration with other body fluids and compartments, by incorporation into body proteins and by metabolic degradation, renal excretion being very small. Amino acid imbalance causes a reduced rate of protein synthesis (Christensen, 1964), as a balanced mixture of all the constituent amino acids must be simultaneously available at the relevant time. If abnormally high serum concentrations of amino acids are caused by an amino acid imbalance, metabolic degradation becomes of especial importance in the disposal of the excess. Amino acids are metabolized either by the known separate pathways of amino acid catabolism or by transamination reactions. Transamination of many other amino acids to alanine is uniquely important in this respect (Felig, 1973). Production of alanine is one of the chief methods of disposal of the excess nitrogen derived from exogenous amino acid loads (Coulson and Hernandez, 1968).

Individual amino acids which were abnormally high in the patients after ingestion of a free amino acid mixture were valine, leucine, proline, and alanine. Similarly, in the imbalance produced in the controls by a deficient free amino acid mixture, increments of alanine, leucine, phenylalanine, and proline were significantly abnormal. Alanine would be expected to be especially high because of the unique importance of this compound in transamination reactions. Proline cannot be transaminated as it has no amino group in the molecule, and therefore degradation of excess amounts of this compound must be by the slower process of proline oxidation. The branched chain amino acids-leucine, isoleucine, and valine-are especially liable to be in high concentration in peripheral blood after free amino acid ingestion, as they are rapidly absorbed by the gut from amino acid mixtures, and are chiefly transaminated to the equivalent ketoacids in voluntary muscle (Manchester, 1965) and not, as occurs in the case of most other amino acids, in the liver (McMenamy, Shoemaker, Richmond, and Elwyn, 1962; Elwyn, Parith, and Shoemaker, 1968). The especial involvement of individual amino acids as evidence of amino acid imbalance in these investigations is thus largely explicable by known aspects of amino acid metabolism. Abnormally high serum concentrations of alanine and of proline were the most definitive evidence of amino acid imbalance in the cystinurics after free amino acid ingestion and in the controls after the intake of the deficient mixture.

Leucine, isoleucine, valine, lysine, and methionine serum increments were significantly higher in the controls after the balanced free amino acid mixture than after Casilan intake. This largely agrees with the results of Silk, Marrs, Addison, Burston, Clark, and Matthews (1973), who studied rates of intestinal absorption in man of tryptic digests of casein and of an equivalent free amino acid mixture. Individual amino acids which were more rapidly absorbed from the mixture were methionine, leucine, isoleucine, valine, and proline, although these results were not significant statistically, the other amino acids being more rapidly taken up from the casein digest.

\section{References}

Asatoor, A. M., Crouchman, M. R., Harrison, A. R., Light, F. W., Loughridge, L. W., Milne, M. D., and Richards, A. J. (1971). Intestinal absorption of oligopeptides in cystinuria. Clin. Sci., 41, 23-33.

Asatoor, A. M., Harrison, B. D. W., Milne, M. D., and Prosser, D. I (1972). Intestinal absorption of an arginine-containing peptide in cystinuria. Gut, 13, 95-98.

Christensen, H. N. (1964). In Mammalian Protein Metabolism, edited by H. N. Munro and J. B. Allison, Vol. 1, p. 109. Academic Press, New York and London.

Colliss, J. E., Levi, A. J., and Milne, M. D. (1963). Stature and nutrition in cystinuria and Hartnup disease. Brit. med. J., 1, 590-592.

Coulson, R. A. and Hernandez, T. (1968). Amino acid catabolism in the intact rat. Amer. J. Physiol., 215, 741-746.

Elwyn, D. H., Parikh, H. C., and Shoemaker, W. C. (1968). Amino acid movements between gut, liver, and periphery in unanaesthetized dogs. Amer. J. Physiol., 215, 1260-1275.

Felig, P. (1973). The glucose-alanine cycle. Metabolism, 22, 179-207.

Hellier, M. D., Holdsworth, C. D., Perrett, D., and Thirumalai, C. (1972). Intestinal dipeptide transport in normal and cystinuric subjects. Clin. Sci., 43, 659-668. 
McCarthy, C. F., Borland, J. L., Jr., Lynch, H. J., Jr., Owen, E. E., and Tyor, M. P. (1964). Defective uptake of basic amino acids and 1-cystine by intestinal mucosa of patients with cystinuria. J. clin. Invest., 43, 1518-1524.

McMenamy, R. H., Shoemaker, W. C., Richmond, J. E., and Elwyn, D. (1962). Uptake and metabolism of amino acids by the dog liver perfused in situ. Amer. J. Physiol., 202, 407-414.

Manchester, K. L. (1965). Oxidation of amino acids by isolated rat diaphragm and the influence of insulin. Biochimica biophysica Acta, 100, 295-298.
Milne, M. D., Asatoor, A. M., Edwards, K. D. G., and Loughridge, L. W. (1961). The intestinal absorption defect in cystinuria. Gut, 2, 323-337.

Rosenberg, L. E. (1966). Cystinuria : genetic heterogeneity and allelism. Science, 154, 1341-1343.

Silk, D. B. A., Marrs, T. C., Addison, J. M., Burston, D., Clark, M. L., and Matthews, D. M. (1973). Absorption of amino acids from an amino acid mixture simulating casein and a $\overline{\bar{C}}$ tryptic hydrolysate of casein in man. Clin. Sci., 45, 715-719.

\section{The May 1974 Issue}

\section{THE MAY 1974 ISSUE CONTAINS THE FOLLOWING PAPERS}

Identity of a newly isolated human polyomavirus from a patient with progressive multifocal leucoencephalopathy ANNE M. FIELD, SYLVIA D. GARDNER, R. A. GOODBODY, AND M. A. WOODHOUSE

Asymptomatic liver disease in hepatitis $\mathbf{B}$ antigen carriers I. L. WOOLF, B. E. BOYES, D. M. JONES, J. S. WHITTAKER, E. TAPP, R. N. M. MacSWEEN, P. H. RENTON, F. STRATTON, AND I. W. DYMOCK

Increased incidence of HL-A 1 and 8 in patients showing IgG or complement coating on their red cells J. A. G. DA COSTA, A. G. WHITE, A. C. PARKER, AND G. B. GRIGOR

The effect of ambient temperature on the anti-D assay using the AutoAnalyzer H. H. GUNSON, P. K. PHILLIPS, AND F. STRATTON

Preparation of test cells for the antiglobulin test FRED STRATTON AND VIOLET I. RAWLINSON

A comparative study of some commercially available tests for rheumatoid factor R. N. M. MacSWEEN, HAZEL HUGHES, CATRIONA BREEN, P. KITCHEN, BRENDA CATHCART, AND W. W. BUCHANAN

An evaluation of absorbent granule kits for determining serum thyroxine concentration and free thyroxine index in the diagnosis of thyroid function T. K. BELL, D. A. BOYLE, D. A. D. MONTGOMERY, AND S. J. TODD

Conventional and dual competitive binding analyses of thyroxine using the Thyopac-4 kit SATOSHI HAMADA, KANJI TORIZUKA, AND TETSUO UETE

Comprehensive one-day renal function testing in man A. Z. GYÖRY, K. D. G. EDWARDS, J. H. STEWART, AND H. M. WHYTE
The nature of the serum alkaline phosphatases in liver diseases C. P. PRICE AND H. G. SAMMONS

The nitroblue-tetrazolium test following acute $\stackrel{0}{\circ}$ myocardial infarction J. SHAFAR, G. BEHR, AND J. RUSIUS

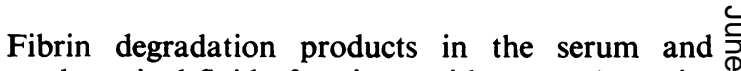
cerebrospinal fluid of patients with group A meningococcal meningitis M. J. BRUETON, P. TUGWELL, H. C. WHITTLE, AND B. M. GREENWOOD

A one-day selective migration procedure for detecting salmonellae in faeces $P$. Y. CHAU AND c. T. HUANG

Gram-positive, motile, cluster-forming cocci as a $\overline{\bar{o}}$ cause of urinary infection s. VIRTANEN

The effect of the dye neutral red on a strain of Staphylococcus aureus in the presence of sunlight B. CHATTOPADHYAY

Changes in the oral flora in Sjögren's syndrome T. W. MaCFARLANE AND D. K. MASON

The reliability of methicillin sensitivity tests on four culture media D. F. J. BROWN AND D. KOTHARI

The signing of laboratory reports G. K. MCGOWAN

Technical methods

Antibiotic sensitivity testing: A modification of the Stokes method using a rotary plater C. H. PEARSON 6 AND J. E. M. WHITEHEAD

Letter to the Editor

Book reviews

Copies are still available and may be obtained from the PUBLISHING MANAGER, BRITISH MEDICAL ASSOCIATION, TAVISTOCK SQUARE, LONDON WC1H 9JR, price $£ 1.05$ 